\title{
Microwave-Mediated Heterocyclization to
}

\section{Benzimidazo[2,1-b]quinazolin-12(5H)-ones}

\author{
Richard D. Carpenter, ${ }^{\dagger}$ Kit S. Lam, ${ }^{\ddagger}$ and Mark J. Kurth ${ }^{\dagger, *}$ \\ ${ }^{\dagger}$ Department of Chemistry, University of California, Davis, One Shields Ave., Davis, CA, 95616. \\ ${ }^{\ddagger}$ Division of Hematology and Oncology, UC Davis Cancer Center, University of California, Davis, CA \\ mjkurth@ucdavis.edu
}

\section{Supporting Information Table of Contents}

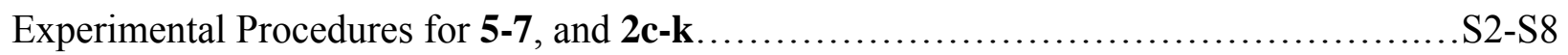

${ }^{1} \mathrm{H}$ and ${ }^{13} \mathrm{C}$ NMR Spectra of 6, 2b-d, and 2h-k...................................S9-S16 


\section{Experimental}

General Procedures. All chemicals were purchased from commercial suppliers and used without further purification. Analytical TLC was carried out on pre-coated plates (silica gel 60, F254) and visualized with UV light. NMR spectra $\left({ }^{1} \mathrm{H}\right.$ at $300 \mathrm{MHz}, 400 \mathrm{MHz},{ }^{13} \mathrm{C}$ at $\left.75 \mathrm{MHz}, 100 \mathrm{MHz}\right)$ were recorded in DMSO- $\mathrm{d}_{6}$ and acetone- $\mathrm{d}_{6}$ as solvents and chemical shifts are expressed in parts per million related to internal TMS. The specifications of the LC/MS are as follows: electrospray (+) ionization, mass range 100-900 Da, $20 \mathrm{~V}$ cone voltage, and Xterra ${ }^{\circledR} \mathrm{MS} \mathrm{C}_{18}$ column $(2.1 \mathrm{~mm} \times 50 \mathrm{~mm} \times 3.5 \mu \mathrm{m})$. $\mathrm{CC}$ refers to column chromatography. Concentration refers to rotary evaporation under reduced pressure. For optimizing the formation of benzimidazoquinazolinone, we examined various acids (2M

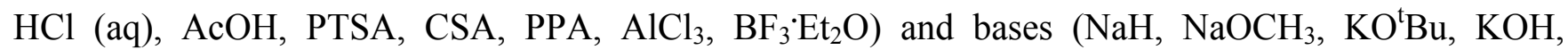
$\left.\mathrm{Ba}(\mathrm{OH})_{2} \cdot 8 \mathrm{H}_{2} \mathrm{O}, \mathrm{K}_{2} \mathrm{CO}_{3}, \mathrm{Et}_{3} \mathrm{~N}, \mathrm{DIPEA}, \mathrm{DBU}\right)$ in varying quantities (catalytic, stoichiometric, excess). We also examined solvents (DMF, THF, dioxane, $\mathrm{H}_{2} \mathrm{O}, \mathrm{CH}_{3} \mathrm{OH}, \mathrm{CH}_{2} \mathrm{Cl}_{2}, \mathrm{C}_{6} \mathrm{H}_{6}$ ) and subjected these reactions to different temperatures (rt, reflux) via different heating elements (conventional oil bath, $\mu \mathrm{W}$ ) and monitored these reactions over different time (30 min, $1 \mathrm{~h}, 5 \mathrm{~h}, 10 \mathrm{~h}, 15 \mathrm{~h})$. 4-Hydroxybutyl polystyrene resin (3.5 mmol/g loading, 200-400 mesh) was purchased from Novabiochem, (batch number A276438). After each solid-phase step, the resin was washed by sequential treatment with the following solvents: DMF (2 x $5 \mathrm{~mL}), \mathrm{H}_{2} \mathrm{O}(2 \times 5 \mathrm{~mL}), \mathrm{CH}_{3} \mathrm{OH},(3 \times 5 \mathrm{~mL})$, and $\mathrm{CH}_{2} \mathrm{Cl}_{2}(5 \times 5 \mathrm{~mL})$. The temperature was maintained using Personal Chemistry Emrys Optimizer microwave reactor, which heated the sealed samples to $160^{\circ} \mathrm{C}$ in $155 \mathrm{sec}$ and maintained that temperature for the duration of the 26 min reactions.

\section{General Procedure for Aryl Isothiocyanate Esters: Methyl-4-Bromo-2-Isocyanatobenzoate (5).} A solution of thiophosgene $(30.0 \mathrm{mmol}, 2.30 \mathrm{~mL})$ in ethyl acetate $(130 \mathrm{~mL})$ was cooled to $-78^{\circ} \mathrm{C}$, followed by the dropwise addition of a solution of triethylamine $(60.1 \mathrm{mmol}, 8.37 \mathrm{~mL})$ in ethyl acetate $(80 \mathrm{~mL})$ dropwise over $30 \mathrm{~min}$. After vigorous stirring for $10 \mathrm{~min}$, a solution of appropriate methyl anthranilate [methyl 4-bromo-anthranilate $(6.28 \mathrm{~g}, 27.3 \mathrm{mmol})]$ in ethyl acetate $(80 \mathrm{~mL})$ was added over 
$30 \mathrm{~min}$, followed by the reaction proceeding to room temperature over $12 \mathrm{~h}$. The workup consisted of diluting with ethyl acetate, followed by washing sequentially with water $(200 \mathrm{~mL}$ x 2$)$ and brine (200 $\mathrm{mL})$. The organic layer was dried $\left(\mathrm{MgSO}_{4}\right)$, concentrated, and the crude product was purified via short path CC (hexanes/ethyl acetate, 9:1) to give 5 (6.76 g, 91\% yield). The analytical data are in accord with literature values. ${ }^{1}$

Dimethyl 4-isothiocyanatoisophthalate (6). Using the General Procedure for Aryl Isothiocyanate Esters, dimethyl 4-aminoisophthalate was transformed into the light red solid 6 (2.24 g, 90\%): mp 48 ${ }^{\circ} \mathrm{C}$; IR (neat): 2215, 1734, $1718 \mathrm{~cm}^{-1} ;{ }^{1} \mathrm{H}$ NMR $\left(400 \mathrm{MHz}\right.$, acetone-d $\left.\mathrm{d}_{6}\right) \delta 8.06(\mathrm{~d}, 1 \mathrm{H}, \mathrm{J}=9.2 \mathrm{~Hz}), 7.97$ $(\mathrm{dd}, 1 \mathrm{H}, J=1.6 \mathrm{~Hz}, J=6.8 \mathrm{~Hz}), 7.93(\mathrm{~d}, 1 \mathrm{H}, J=1.6 \mathrm{~Hz}), 3.96(\mathrm{~s}, 3 \mathrm{H}), 3.94(\mathrm{~s}, 3 \mathrm{H}) ;{ }^{13} \mathrm{C} \mathrm{NMR}(100$ MHz, acetone- $\left.\mathrm{d}_{6}\right) \delta 172.1,165.2,164.7,135.5,132.6,131.1,130.7,129.2,128.4,53.2,53.1$; ESI MS m/z $195(-\mathrm{NCS}, \mathrm{M}+\mathrm{H})^{+}$. Anal. Calcd for $\mathrm{C}_{11} \mathrm{H}_{9} \mathrm{NO}_{4} \mathrm{~S} \mathrm{C}, 52.58 ; \mathrm{H}, 3.61 ; \mathrm{N}, 5.57$. Found $\mathrm{C}, 52.60 ; \mathrm{H}$, 3.60; N, 5.58. Purity was determined to be $98 \%$ by HPLC analysis on the basis of absorption at $220 \mathrm{~nm}$.

\section{General Procedure for Aryl Isothiocyanate Ester Resins: 4-Bromo-2(4-hydroxybutyl-} polystyrene) o-isothiocyanatobenzoate (8). 4-Hydroxybutylpolystyrene resin ( $1 \mathrm{~g}, 3.5 \mathrm{mmol})$ was swelled in DMF (30 mL) for $16 \mathrm{~h}$, followed by coupling 4-bromo-2-nitrobenzoic acid (2.92 g, 17.5 mmol) with 2-(1H-benzotriazoloe-1-yl)-1,1,3,3-tetramethyluronium hexafluorophosphate (HBTU, 6.64 $\mathrm{g}, 17.5 \mathrm{mmol})$ and DIEA $(17.5 \mathrm{mmol}, 3.09 \mathrm{~mL})$ for $8 \mathrm{~h}$. After draining and washing, this aryl nitro resin was reduced with $\mathrm{SnCl}_{2} \cdot 2 \mathrm{H}_{2} \mathrm{O}(23.7 \mathrm{~g}, 105 \mathrm{mmol})$ in DMF $(30 \mathrm{~mL})$ for $4 \mathrm{~h}$. After draining, washing, and a positive chloranil test, ${ }^{2}$ this aniline resin was slowly treated with a solution of thiophosgene (10.5 $\mathrm{mmol}, 804 \mu \mathrm{L})$ and $\mathrm{Et}_{3} \mathrm{~N}(23.0 \mathrm{mmol}, 3.20 \mathrm{~mL})$ in EtOAc $(30 \mathrm{~mL})$. After $16 \mathrm{~h}$, the resin was dried, washed, and vacuum dried to give the aryl isothiocyanate resin 8: IR (neat): $2125,1740,1057,688 \mathrm{~cm}^{-1}$.

Benzimidazo[2,1-b]quinazoline-12(5H)-one (2a). Employing the General Procedure for SolidPhase Benzimidazoquinazolinones with aryl isothiocyanate resin 7 and $o$-phenylenediamine also gave 2a (382 mg, 93\%). See Experimental Section in the manuscript for analytical data.

8-Bromobenzimidazo[2,1-b]quinazoline-12(5H)-one (2b). Employing the General Procedure for 
Solution-Phase Benzimidazoquinazolinones with aryl isothiocyanate $\mathbf{4}$ and 4-bromo-ophenylenediamine also delivered $2 \mathbf{b}$ (326 mg, 94\%). See Experimental Section in the manuscript for analytical data.

\section{General Procedure for Solution-Phase Benzimidazoquinazolinones: 2-Bromobenzimidazo[2,1-}

b]quinazoline-12(5H)-one (2c). To a solution of an appropriate diamine (e.g., o-phenylenediamine; $176 \mathrm{mg}, 1.63 \mathrm{mmol})$ in $\mathrm{CH}_{2} \mathrm{Cl}_{2}(8 \mathrm{~mL})$ was added an appropriate aryl isothiocyanate ester (e.g, $4 \mathbf{b} ; 422$ $\mathrm{mg}, 1.55 \mathrm{mmol})$ in $\mathrm{CH}_{2} \mathrm{Cl}_{2}(8 \mathrm{~mL})$ dropwise over $30 \mathrm{~min}$. After $16 \mathrm{~h}$, DIC (4.65 mmol, $\left.691 \mu \mathrm{L}\right)$ was added and the reaction was monitored by TLC. In most instances, the reaction was completed in $10 \mathrm{~h}$, although the reaction times ranged between 6 and $18 \mathrm{~h}$. Following completion, the solvent was concentrated before recrystallization with hot $\mathrm{CHCl}_{3}$ and petroleum ether afforded a mixture of benzimidazole ester (70\%) and benzimidazoquinazoline 2c (30\%). This mixture (480 mg) was dissolved in dioxane, and transferred to a $5 \mathrm{~mL}$ round bottom microwave vial. To this mixture was added barium hydroxide octahydrate $(2.57 \mathrm{~g}, 8.15 \mathrm{mmol})$, followed by sealing the vessel and heating to $160{ }^{\circ} \mathrm{C}$ for $26 \mathrm{~min}$ in a microwave reactor (Personal Chemistry, Emrys Optimizer). The reaction temperature increased from 25 to $160{ }^{\circ} \mathrm{C}$ in $155 \mathrm{sec}$, and was maintained at $160{ }^{\circ} \mathrm{C}$ for the duration, at which point the bright yellow precipitate was filtered and washed with aq. $\mathrm{NH}_{4} \mathrm{Cl}, \mathrm{H}_{2} \mathrm{O}$, dioxane, $\mathrm{CH}_{2} \mathrm{Cl}_{2}$ and EtOAc to afford 2c (435 mg 94\% yield): mp 355-356 ${ }^{\circ} \mathrm{C}$; IR (neat): 3339 (sh), 1686, 1038 $\mathrm{cm}^{-1} ;{ }^{1} \mathrm{H}$ NMR (300 MHz, DMSO-d 6 ) $\delta 8.37(\mathrm{~d}, 1 \mathrm{H}, J=7.2 \mathrm{~Hz}), 8.14(\mathrm{~s}, 1 \mathrm{H}), 7.54(\mathrm{~d}, 1 \mathrm{H}, J=9.2 \mathrm{~Hz})$, $7.36(\mathrm{~d}, 1 \mathrm{H}, J=8.4 \mathrm{~Hz}), 7.30(\mathrm{dd}, 1 \mathrm{H}, J=2.0, J=6.8 \mathrm{~Hz}), 7.24(\mathrm{~d}, 1 \mathrm{H}, J=7.6 \mathrm{~Hz}) ;{ }^{13} \mathrm{C}$ NMR $(75$ MHz, DMSO-d $\left.{ }_{6}\right) \delta 159.9,155.1,151.0,145.4,134.6,128.2,127.9,127.2,124.1,116.4,114.6,114.3$, 113.9, 107.7, 104.3; ESI MS m/z 314, $316(\mathrm{M}+\mathrm{H})^{+}$; Anal. Calcd for $\mathrm{C}_{14} \mathrm{H}_{8} \mathrm{BrN}_{3} \mathrm{O}$ C, 53.53; $\mathrm{H}, 2.57 ; \mathrm{N}$, 13.38. Found C, 53.51; H, 2.57; N, 13.39. Purity of the crude product was determined to be $99 \%$ by HPLC analysis on the basis of absorption at $220 \mathrm{~nm}$.

2-Bromobenzimidazo[2,1-b]quinazoline-12(5H)-one (2c). Employing the General Procedure for Solid-Phase Benzimidazoquinazolinones with aryl isothiocyanate resin 8 and o-phenylenediamine also 
gave 2c (467 mg, 85\%).

\section{General Procedure for Solid-Phase Benzimidazolequinazolinone: 2-Bromo-8-methyl-} benzimidazo[2,1-b]quinazoline-12(5H)-one (2d). Aryl isothiocyanate resin 8 (1.0 g, $3.5 \mathrm{mmol})$ was split into two flasks and each flask received an appropriate o-phenylenediamine [4-methyl-ophenylenediamine $(2.72 \mathrm{~g}, 10.5 \mathrm{mmol})]$ and allowed to react for $16 \mathrm{~h}$. DIC (10.5 mmol, $1.63 \mathrm{~mL})$ was then added, and the reaction went for an additional $16 \mathrm{~h}$. This benzimidazole resin was transferred to a $5 \mathrm{~mL}$ microwave vial, and to this resin was added barium hydroxide octahydrate $(3.31 \mathrm{~g}, 10.5 \mathrm{mmol})$ in DMF (3 mL). The vessel was sealed and heated to $160{ }^{\circ} \mathrm{C}$ for $26 \mathrm{~min}$ in a microwave reactor (Personal Chemistry, Emrys Optimizer). The resin was filtered and washed with warm DMF. The filtrate was diluted with $0.5 \mathrm{M} \mathrm{NH}_{4} \mathrm{Cl}(15 \mathrm{~mL})$ and extracted with EtOAc $(2 \times 10 \mathrm{~mL})$. The combined organic layers were washed with water $(3 \times 20 \mathrm{~mL})$ and brine $(1 \times 10 \mathrm{~mL})$ followed by drying $\left(\mathrm{MgSO}_{4}\right)$ and concentration to afford 2d (528 $\mathrm{mg}, 92 \%)$ as a yellow solid: $\mathrm{mp} 375-376{ }^{\circ} \mathrm{C}$; IR (neat): 3327 , 1716,1688, $1045 \mathrm{~cm}^{-1} ;{ }^{1} \mathrm{H}$ NMR (300 MHz, DMSO-d $) \delta 8.53(\mathrm{~s}, 1 \mathrm{H}), 8.32(\mathrm{~d}, 1 \mathrm{H}, J=3.6 \mathrm{~Hz}), 8.14(\mathrm{~d}$, $1 \mathrm{H}, J=3.9 \mathrm{~Hz}), 7.72(\mathrm{~s}, 1 \mathrm{H}), 7.52($ apparent s, 1H), $7.19(\mathrm{~d}, 1 \mathrm{H}, J=3.9 \mathrm{~Hz}), 6.91(\mathrm{~d}, 1 \mathrm{H}, J=3.9 \mathrm{~Hz})$, $2.57(\mathrm{~s}, 3 \mathrm{H}) ;{ }^{13} \mathrm{C}$ NMR $\left(75 \mathrm{MHz}, \mathrm{DMSO}_{-} \mathrm{d}_{6}\right) \delta 162.5,160.3,149.7,143.8,139.9,129.9,125.8,125.2$, 122.3, 120.4, 119.7, 115.1, 114.2, 113.8, 21.7; ESI MS m/z 328, $330(\mathrm{M}+\mathrm{H})^{+}$; Anal. Calcd for $\mathrm{C}_{15} \mathrm{H}_{10} \mathrm{BrN}_{3} \mathrm{O} \mathrm{C}, 54.90 ; \mathrm{H}, 3.07 ; \mathrm{N}, 12.80$. Found $\mathrm{C}, 55.06 ; \mathrm{H}, 3.06 ; \mathrm{N}, 12.77$. Purity of the crude product was determined to be $97 \%$ by HPLC analysis on the basis of absorption at $220 \mathrm{~nm}$.

2-Bromo-8-methylbenzimidazo[2,1-b]quinazoline-12(5H)-one (2d). Employing the General Procedure for Solution-Phase Benzimidazoquinazolinones with aryl isothiocyanate 5 and 4-methyl-ophenylenediamine also delivered 2d (458 mg, 95\%).

\section{Methyl 12(5H)-oxobenzimidazo[2,1-b]quinazolin-9-carboxylate (2e). Using the General} Procedure for Solution-Phase Benzimidazoquinazolinones with aryl isothiocyanate 4 and 4-methyl-ophenylenediamine delivered 2e (352 mg, 91\%). Employing the General Procedure for Solid-Phase Benzimidazoquinazolinones with aryl isothiocyanate resin 7 and 4-methyl-o-phenylenediamine also 
delivered 2e as a yellow solid (349 mg, 90\%). The analytical data are in accord with literature values. ${ }^{3}$

8-Chlorobenzimidazo[2,1-b]quinaziline-12(5H)-one (2f). Using the General Procedure for Solution-Phase Benzimidazoquinazolinones with aryl isothiocyanate $\mathbf{4}$ and 4-chloro-ophenylenediamine delivered 2f (571mg, 91\%). Employing the General Procedure for Solid-Phase Benzimidazoquinazolinones with aryl isothiocyanate resin 7 and 4-chloro-o-phenylenediamine also delivered $2 \mathbf{f}(373 \mathrm{mg}, 88 \%)$. The analytical data are in accord with literature values. ${ }^{3}$

8-Methoxybenzimidazo[2,1-b]quinaziline-12(5H)-one (2g). Using the General Procedure for Solution-Phase Benzimidazoquinazolinones with aryl isothiocyanate $\mathbf{4}$ and 4-methoxy-ophenylenediamine delivered $\mathbf{2 g}$ (744 mg, 96\%). Employing the General Procedure for Solid-Phase Benzimidazoquinazolinones with aryl isothiocyanate resin 7 and 4-methoxy-o-phenylenediamine also delivered $\mathbf{2 g}$ as a yellow solid (381 mg, 91\%). The analytical data are in accord with literature values. ${ }^{3}$

Methyl 2-bromo-12(5H)-oxobenzimidazo[2,1-b]quinazolin-9-carboxylate (2h). Using the General Procedure for Solution-Phase Benzimidazoquinazolinones, delivered $2 \mathbf{h}$ (333 mg, 92\%). Employing the General Procedure for Solid-Phase Benzimidazoquinazolinones with aryl isothiocyanate 8 and 4carbomethoxy-o-phenylenediamine also delivered $\mathbf{2 h}$ as a yellow solid (478 $\mathrm{mg}, 92 \%): \mathrm{mp} 398-399{ }^{\circ} \mathrm{C}$; IR (neat): 3336 (sh), 1712, 1679, $1019 \mathrm{~cm}^{-1} ;{ }^{1} \mathrm{H}$ NMR (300 MHz, DMSO-d 6 ) $\delta 8.21(\mathrm{~d}, 1 \mathrm{H}, J=8.7 \mathrm{~Hz})$, 8.12-8.05 (m, 1H), $7.50(\mathrm{dd}, 1 \mathrm{H}, J=2.7 \mathrm{~Hz}, J=7.2 \mathrm{~Hz}) 7.11(\mathrm{dd}, 1 \mathrm{H}, J=2.4 \mathrm{~Hz}, J=6.0 \mathrm{~Hz}), 6.90-6.78$ $(\mathrm{m}, 1 \mathrm{H}), 6.54(\mathrm{dd}, 1 \mathrm{H}, J=2.4 \mathrm{~Hz}, J=8.4 \mathrm{~Hz}) 3.56(\mathrm{~s}, 3 \mathrm{H}) ;{ }^{13} \mathrm{C}$ NMR $\left(75 \mathrm{MHz}, \mathrm{DMSO}-\mathrm{d}_{6}\right) \delta 166.2$, $160.8,156.7,144.7,142.2,130.9,130.1,126.1,120.8,11119.1,118.7,117.9,116.8,115.2,113.9,59.3$; ESI MS m/z 372, $374(\mathrm{M}+\mathrm{H})^{+}$; Anal. Calcd for $\mathrm{C}_{16} \mathrm{H}_{10} \mathrm{BrN}_{3} \mathrm{O}_{3} \mathrm{C}, 51.63 ; \mathrm{H}, 2.71 ; \mathrm{N}, 11.29$. Found C, 51.72; H, 2.70; N, 11.33. Purity of the crude product was determined to be $96 \%$ by HPLC analysis on the basis of absorption at $220 \mathrm{~nm}$.

Methyl 8-bromo-12(5H)-oxobenzimidazo[2,1-b]quinazolin-2-carboxylate (2i). Using the General Procedure for Solution-Phase Benzimidazoquinazolinones with aryl isothiocyanate 6 and 4-bromo-ophenylenediamine delivered $2 \mathbf{i}$ (392 $\mathrm{mg}, 94 \%$ ) as a yellow solid: $\mathrm{mp} 389-390{ }^{\circ} \mathrm{C}$; IR (neat): 3324 (sh), 
1733, 1683, $1013 \mathrm{~cm}^{-1} ;{ }^{1} \mathrm{H}$ NMR (300 MHz, DMSO-d $) \delta 8.27$ (d, 1H, J=3.9 Hz), 8.09 (s, 1H), 8.06-

$8.05(\mathrm{~m}, 1 \mathrm{H}), 7.57(\mathrm{t}, 1 \mathrm{H}, J=3.9 \mathrm{~Hz}), 7.43(\mathrm{~s}, 1 \mathrm{H}), 7.04(\mathrm{~d}, 1 \mathrm{H}, J=3.9 \mathrm{~Hz}) 3.56(\mathrm{~s}, 3 \mathrm{H}) ;{ }^{13} \mathrm{C}$ NMR $(75$ MHz, DMSO-d 6 ) $\delta 173.1,160.9$, , 155.9, 152.0, 147.5, 144.9, 142.4, 129.4, 127.6, $126.4,125.0,118.6$, 118.5, 116.5, 113.4, 106.7, 66.4; ESI MS m/z 372, $374(\mathrm{M}+\mathrm{H})^{+}$; Anal. Calcd for $\mathrm{C}_{16} \mathrm{H}_{10} \mathrm{BrN}_{3} \mathrm{O}_{3} \mathrm{C}_{\text {, }}$ 51.63; H, 2.71; N, 11.29. Found C, 51.57; H, 2.71; N, 11.27. Purity of the crude product was determined to be $98 \%$ by HPLC analysis on the basis of absorption at $220 \mathrm{~nm}$.

Dimethyl 12(5H)-oxobenzimidazo[2,1-b]quinazolin-2,8-dicarboxylate (2j). Using the General Procedure for Solution-Phase Benzimidazoquinazolinones with aryl isothiocyanate 6 and 4carbomethoxy-o-phenylenediamine delivered $2 \mathbf{2 j}(615 \mathrm{mg}, 91 \%)$ as a yellow solid: $\mathrm{mp} 388-389{ }^{\circ} \mathrm{C}$; IR (neat): 3330 (sh), 1729, 1716, $1682 \mathrm{~cm}^{-1} ;{ }^{1} \mathrm{H}$ NMR (300 MHz, DMSO-d 6 ) $\delta 8.49(\mathrm{~d}, 1 \mathrm{H}, J=1.5), 8.27$ $(\mathrm{d}, 1 \mathrm{H}, J=8.4), 7.59(\mathrm{dd}, 1 \mathrm{H}, J=3.6 \mathrm{~Hz}, J=4.5 \mathrm{~Hz}), 7.43(\mathrm{~s}, 1 \mathrm{H}), 7.36-7.25(\mathrm{~m}, 1 \mathrm{H}), 3.56(\mathrm{~s}, 3 \mathrm{H})$, $3.52(\mathrm{~s}, 3 \mathrm{H}) ;{ }^{13} \mathrm{C}$ NMR $\left(75 \mathrm{MHz}, \mathrm{DMSO}-\mathrm{d}_{6}\right) \delta 173.2,166.4,160.6,157.8,147.6,144.8,142.1,132.7$, 130.1, 125.2, 120.8, 119.1, 118.7, 115.8, 115.1, 112.9, 66.2, 59.2 ; ESI MS m/z $352(\mathrm{M}+\mathrm{H})^{+}$; Anal. Calcd for $\mathrm{C}_{18} \mathrm{H}_{13} \mathrm{~N}_{3} \mathrm{O}_{5} \mathrm{C}, .61 .54 ; \mathrm{H}, 3.73 ; \mathrm{N}, 11.96$. Found $\mathrm{C}, 61.70 ; \mathrm{H}, 3.74 ; \mathrm{N}, 11.93$. Purity of the crude product was determined to be $95 \%$ by HPLC analysis on the basis of absorption at $220 \mathrm{~nm}$.

\section{Methyl 8-methoxy-12(5H)-oxobenzimidazo[2,1-b]quinazolin-2-carboxylate (2k). Using the}

General Procedure for Solution-Phase Benzimidazoquinazolinones with aryl isothiocyanate 6 and 4methoxy-o-phenylenediamine delivered $2 \mathbf{k}(367 \mathrm{mg}, 98 \%)$ as a yellow solid: $\mathrm{mp} 350-351{ }^{\circ} \mathrm{C}$; IR (neat): 3335 (sh), 1728, 1688, 1251, $1038 \mathrm{~cm}^{-1} ;{ }^{1} \mathrm{H}$ NMR (300 MHz, DMSO-d 6 ) $\delta 8.21(\mathrm{~d}, 1 \mathrm{H}, J=6.6 \mathrm{~Hz})$, $7.83(\mathrm{~d}, 1 \mathrm{H}, J=1.8 \mathrm{~Hz}), 7.28-7.21(\mathrm{~m}, 1 \mathrm{H}), 7.10(\mathrm{dd}, 1 \mathrm{H}, J=2.4 \mathrm{~Hz}, J=4.5 \mathrm{~Hz}), 6.91-6.87(\mathrm{~m}, 1 \mathrm{H})$, 6.56-6.52 (m, 1H) $3.80(\mathrm{~s}, 3 \mathrm{H}), 3.56(\mathrm{~s}, 3 \mathrm{H}) ;{ }^{13} \mathrm{C}$ NMR (75 MHz, DMSO-d 6 ) $\delta 167.3,163.4,160.9$, $160.2,149.3,139.7,133.7,132.6,127.6,127.1,122.7,121.5,114.2,113.9,98.6,66.4,62.2 ;$ ESI MS m/z $324(\mathrm{M}+\mathrm{H})^{+}$; Anal. Calcd for $\mathrm{C}_{17} \mathrm{H}_{13} \mathrm{~N}_{3} \mathrm{O}_{4} \mathrm{C}, 61.54 ; \mathrm{H}, 4.05 ; \mathrm{N}, 13.00$. Found $\mathrm{C}, 61.68 ; \mathrm{H}, 4.06 ; \mathrm{N}$, 13.03. Purity of the crude product was determined to be $98 \%$ by HPLC analysis on the basis of absorption at $220 \mathrm{~nm}$. 


\section{References:}

1. Graefe, I.; Kottke, K.; Kuehmstedt, H.; Knoke, D. Pharmazie 1990, 45, 530.

2. Marik, J.; Song, A.; Lam, K. S. Tetrahedron Lett. 2003, 44, 4319.

3. Bird, C. W.; Kapilli, M. Tetrahedron 1987, 43, 4621. 


\section{Detailed Spectroscopic Data}

6:<smiles>CCOC(=O)c1ccc(N(S)S(=O)(=O)c2ccccc2)c(C(C)=O)c1</smiles>

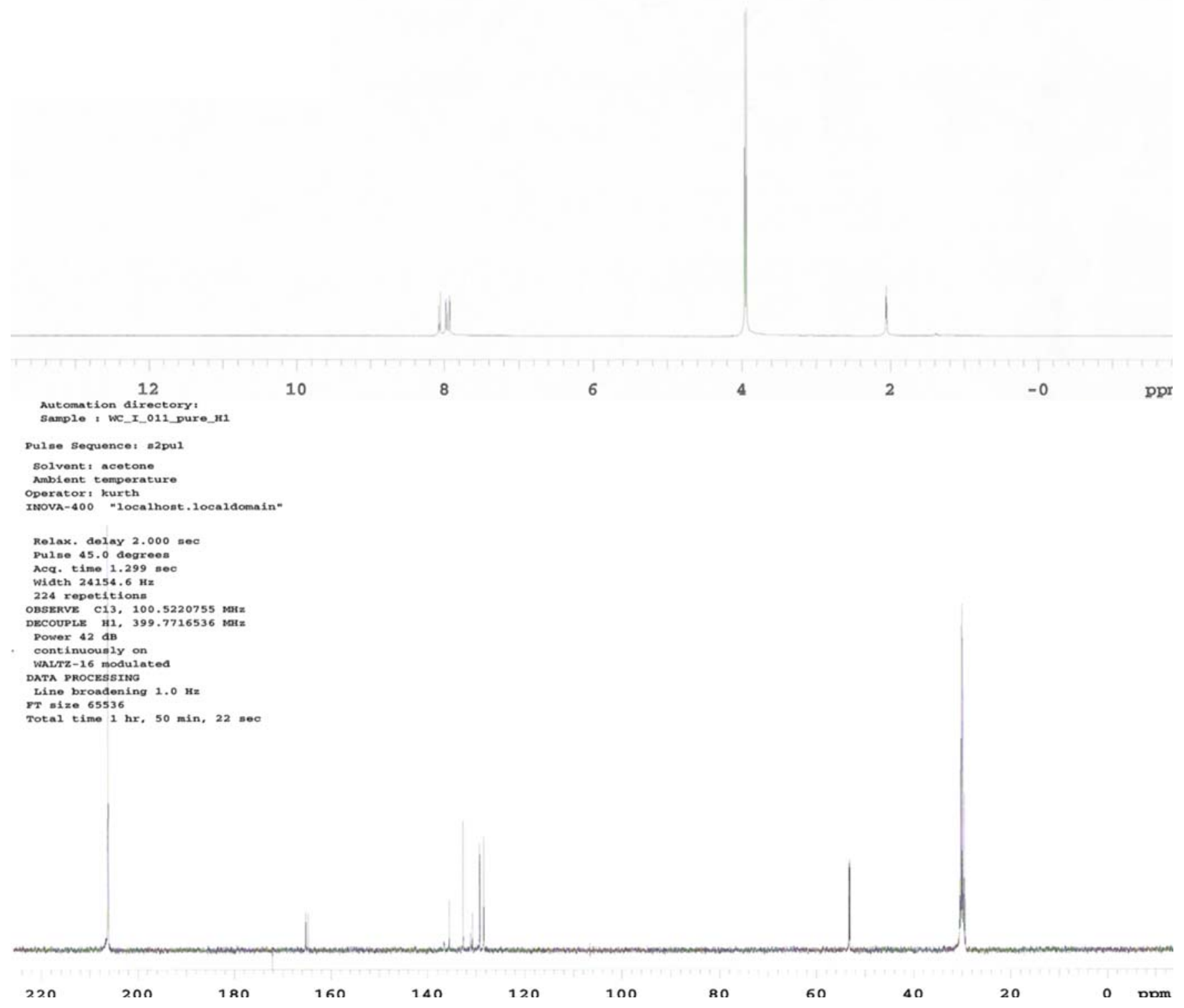


2b:
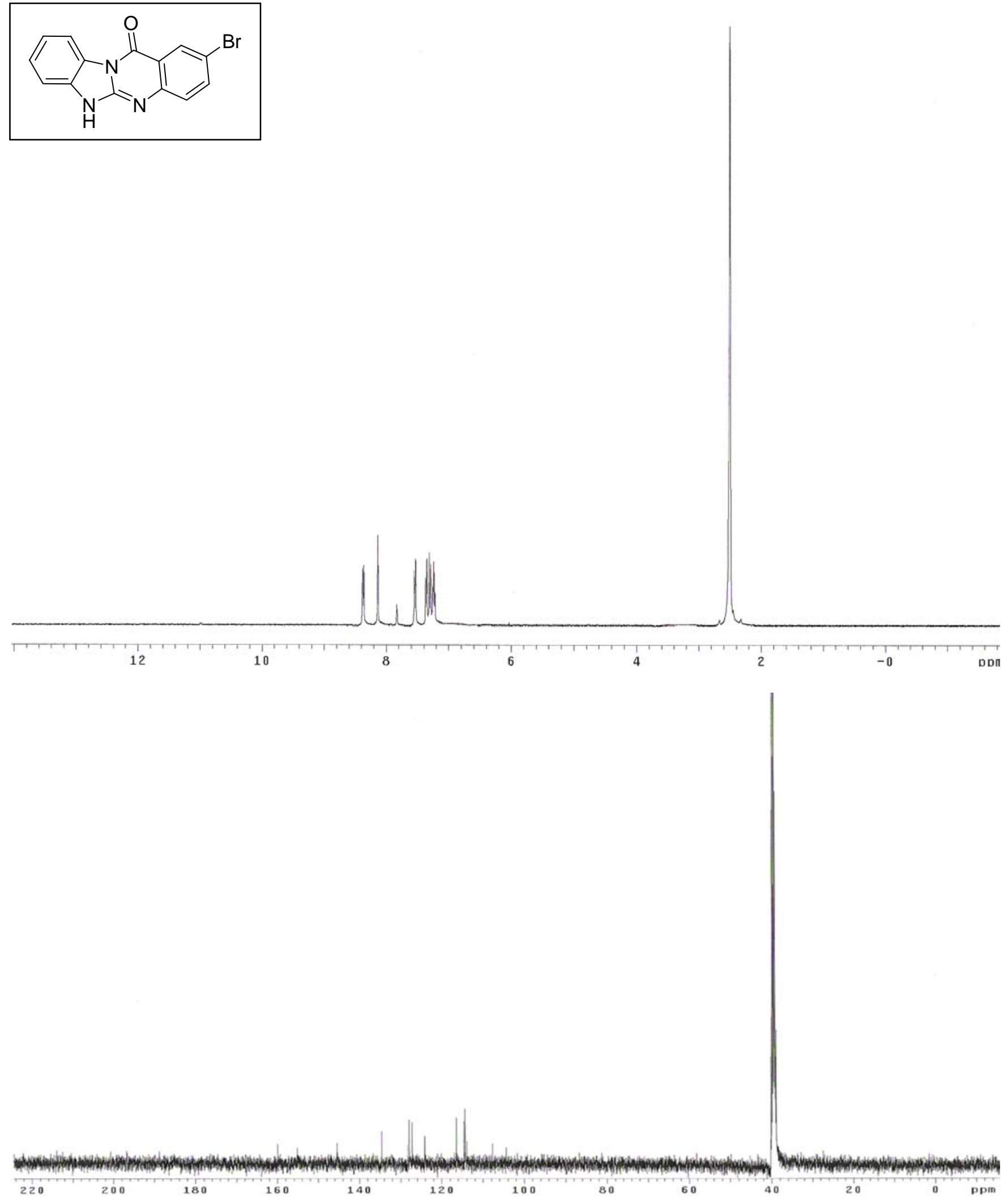
2c:
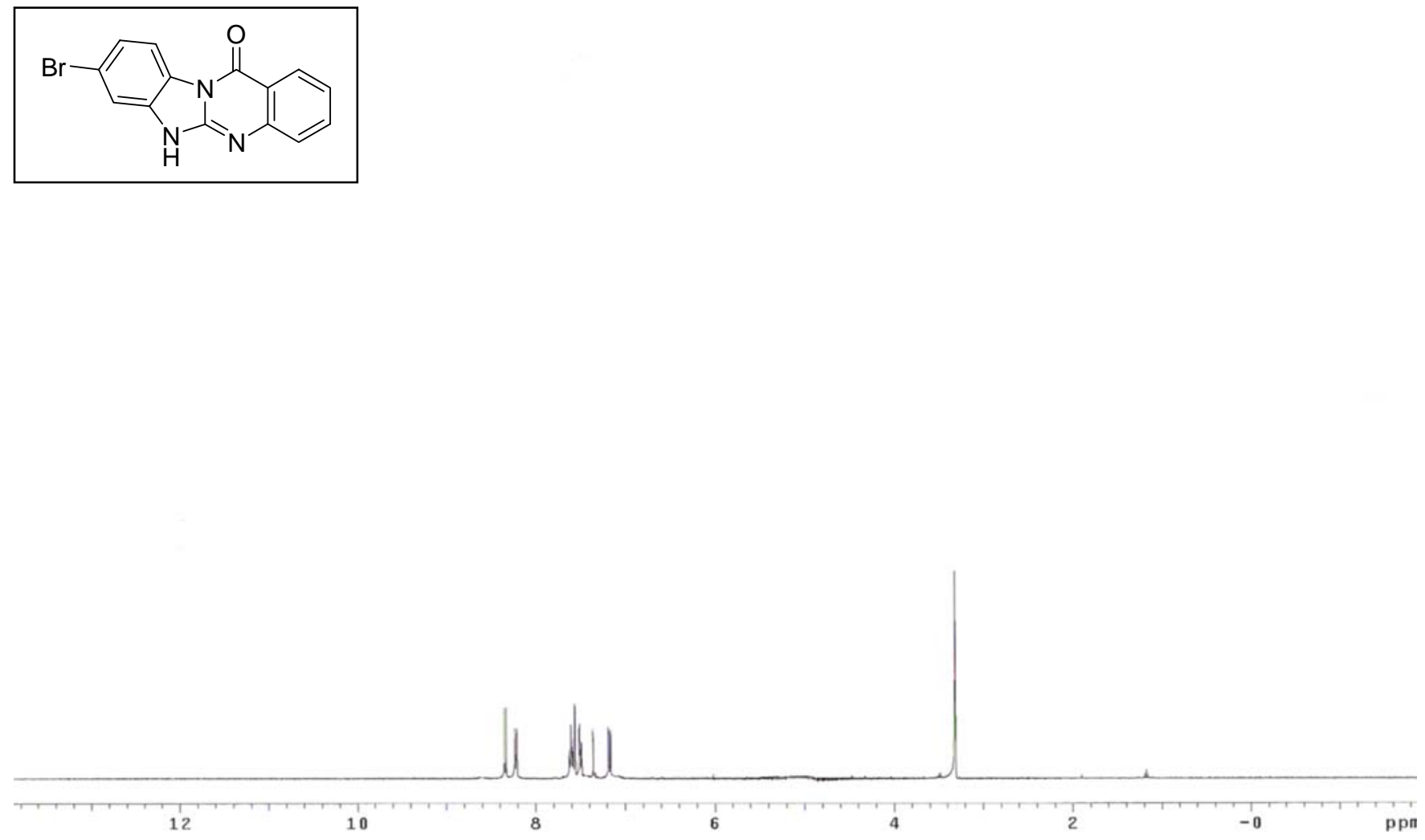

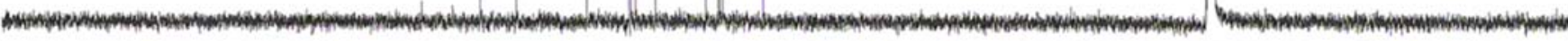

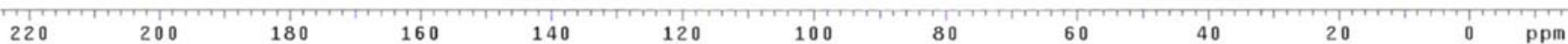

S11 
2d:

Probe tuneing parameter

Automation directory:

Pulse Sequence: s2pul<smiles>Cc1ccc2c(c1)[nH]c1nc3ccccc3c(=O)n12</smiles>

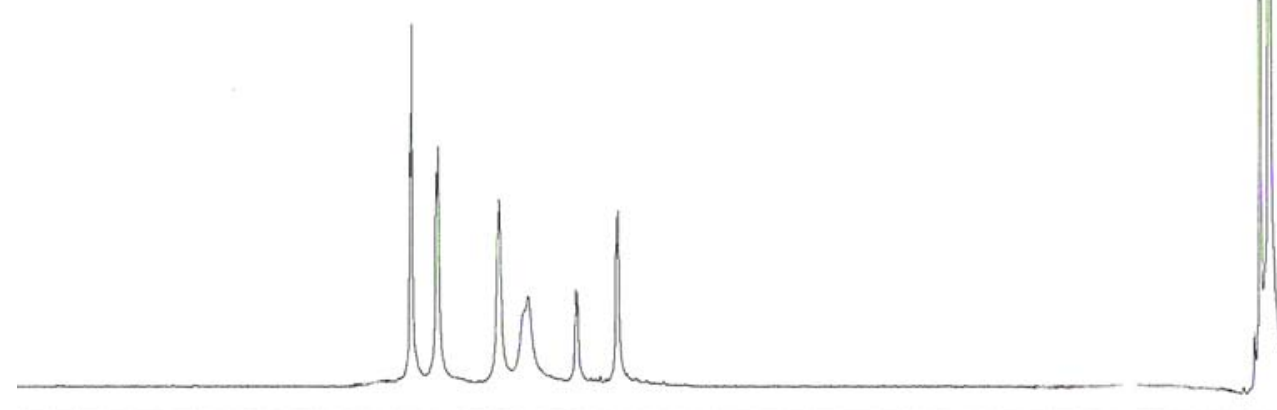

10

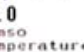

9

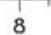

pperator:

Relax, delay 10.000 sec

Relax, de lay 10,000

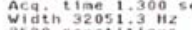

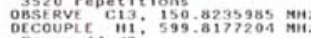

Power 14 de on
continuous Iy on
WAt

onin Proctssinio $1.0 \mathrm{~Hz}$

Fotai itae $15 \mathrm{hr}$. $58 \mathrm{~min}, 15 \mathrm{sec}$

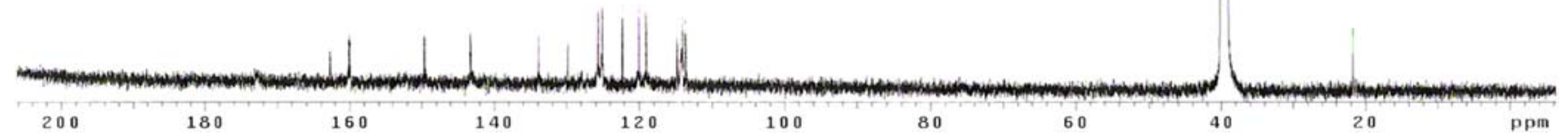


2h:
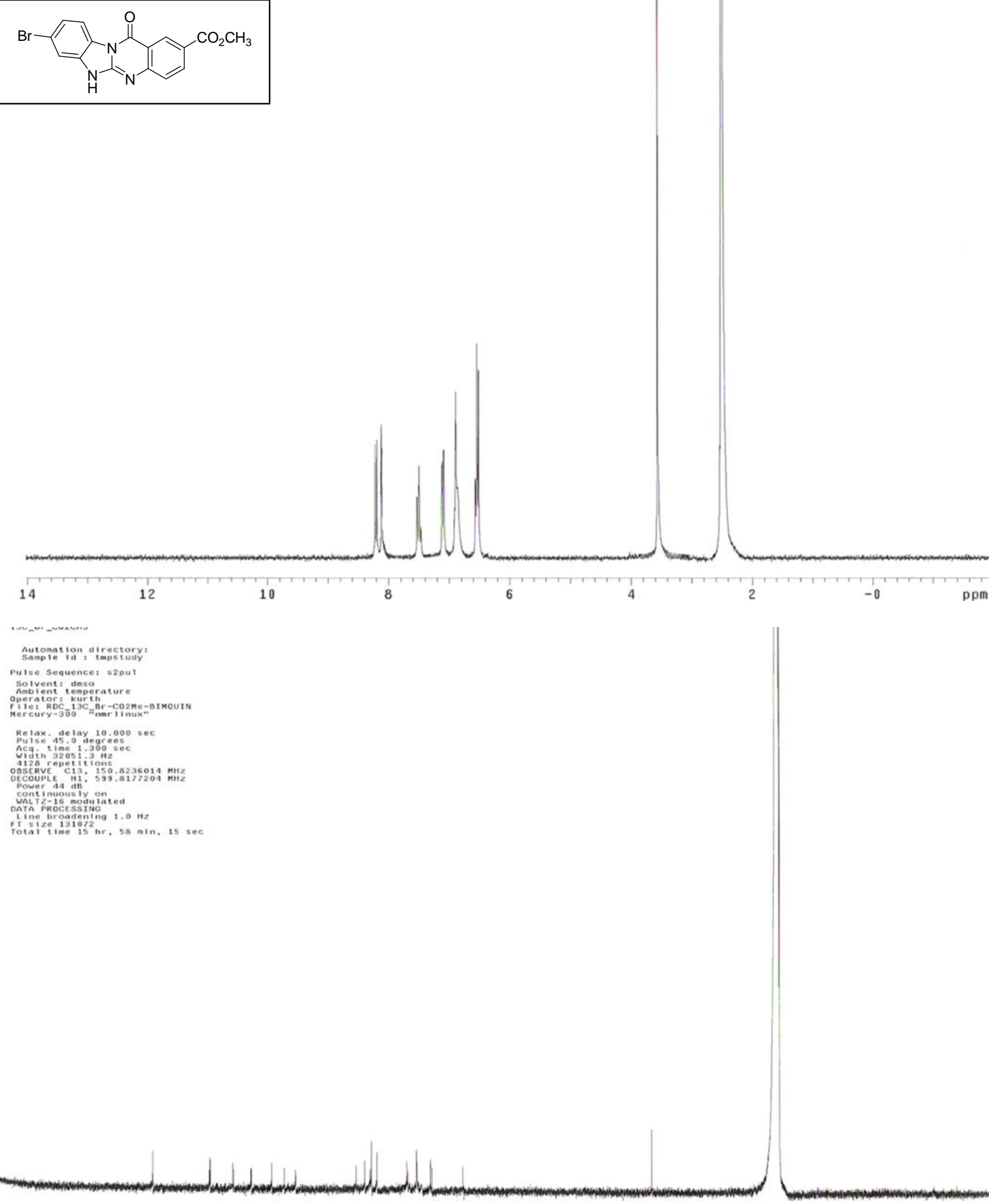
2i:
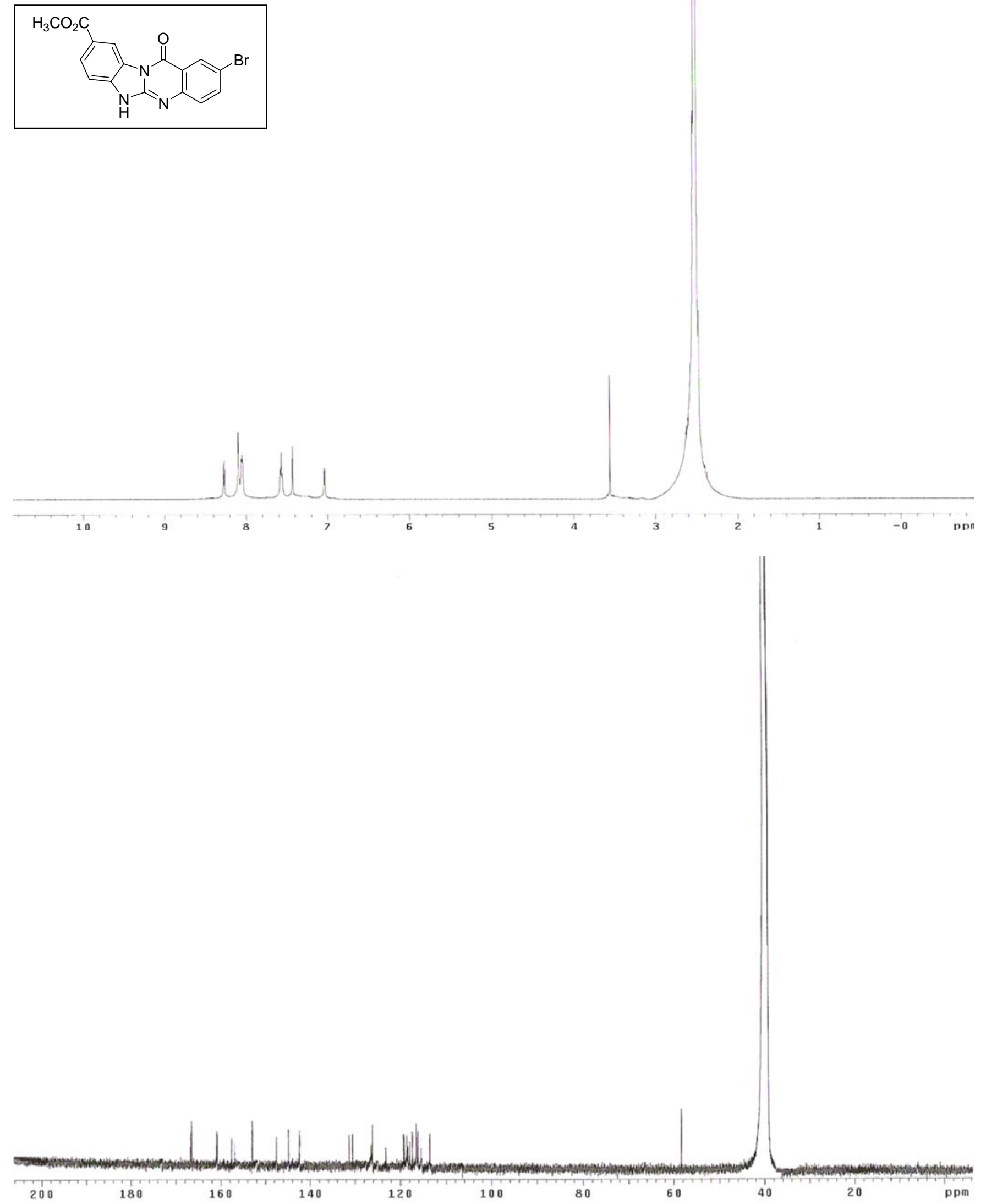
2j:

$\mathrm{H}_{3} \mathrm{CO}_{2} \mathrm{C}$

COC
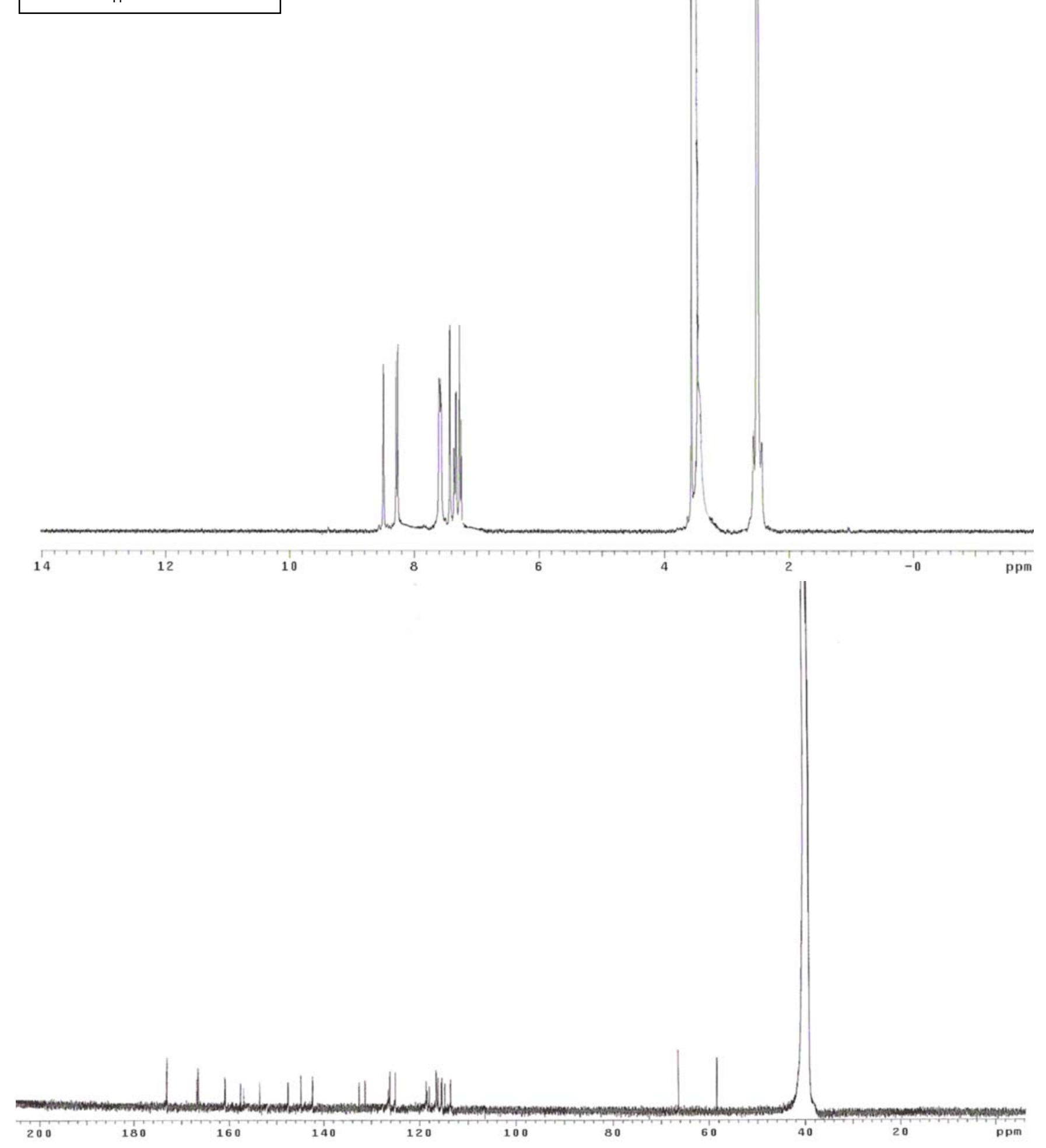
2k:
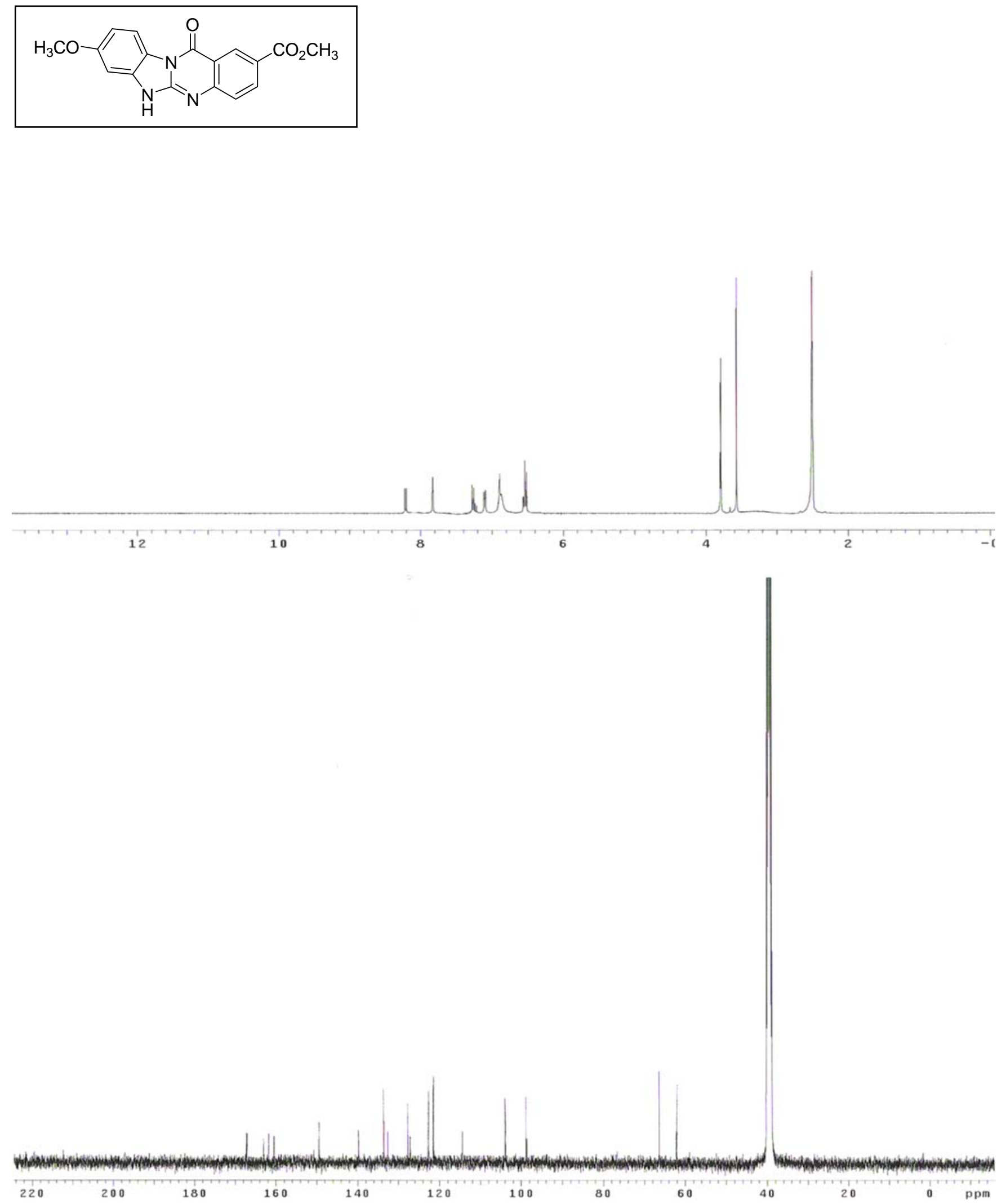